Speed perception and actual speed in a driving simulator and real-world: A validation study

Peer-reviewed author version

HUSSAIN, Qinaat; Alhajyaseen, Wael K.M.; PIRDAVANI, Ali; REINOLSMANN, Nora; BRIJS, Kris \& BRIJS, Tom (2019) Speed perception and actual speed in a driving simulator and real-world: A validation study. In: Transportation research. Part F, Traffic psychology and behaviour, 62, p. 637-650.

DOI: $10.1016 / j . t r f .2019 .02 .019$

Handle: http://hdl.handle.net/1942/27931 


\section{Speed Perception and Actual Speed in a Driving Simulator and Real-world: A Validation Study}

\section{Qinaat Hussain}

Qatar University - Qatar Transportation and Traffic Safety Center, College of Engineering, P.O.Box 2713, Doha, Qatar \&

Uhasselt, Transportation Research Institute (IMOB), Agoralaan, 3590 Diepenbeek, Belgium Tel:+974(0)33531196 Email: qinaat.hussain@qu.edu.qa / qinaat.hussain@uhasselt.be

Wael K. M. Alhajyaseen

Qatar University - Qatar Transportation and Traffic Safety Center, College of Engineering P.O.Box 2713, Doha, Qatar

Tel: +974(0)440366 79 Fax: +974(0)44034302 Email: wyaseen@qu.edu.qa

\section{Ali Pirdavani}

Uhasselt, Faculty of Engineering Technology \&

Uhasselt, Transportation Research Institute (IMOB)

Agoralaan, 3590 Diepenbeek, Belgium

Tel: +32 (0) 11292183 Fax: +32 (0) 11269199 Email: ali.pirdavani@uhasselt.be

\section{Nora Reinolsmann}

Uhasselt, Transportation Research Institute (IMOB)

Agoralaan, 3590 Diepenbeek, Belgium

Tel: +32(0)11 26 9149; Email: nora.reinolsmann@uhasselt.be

\section{Kris Brijs}

Uhasselt, Transportation Research Institute (IMOB)

Agoralaan, 3590 Diepenbeek, Belgium

Tel: +32(0)11269129 Fax: +32(0)112691 99; Email: kris.brijs@uhasselt.be

\section{Tom Brijs}

Uhasselt, Transportation Research Institute (IMOB)

Agoralaan, 3590 Diepenbeek, Belgium

Tel: +32 (0) 11269155 Fax: +32 (0) 11269199 Email: tom.brijs@uhasselt.be 


\title{
Speed Perception and Actual Speed in a Driving Simulator and Real-world: A Validation Study
}

\begin{abstract}
Background: Driving simulators have become an effective research tool in traffic safety, but the validity of results obtained in simulated environments remains a debated issue of high importance. Objective: The objective of this study is to validate a fixed-base driving simulator for speed perception and actual speed and to support its application in traffic safety studies.

Method: The study consisted of two experiments to test the external and ecological validity of the driving simulator in absolute and relative terms. External validity was framed into two parts i.e. for speed perception and actual speed. In the first part, the external validity was assessed based on the speed perception observations from forty volunteers that participated in the study. Speed estimations for four different requested speeds $(50,70,80$ and $100 \mathrm{kph})$ were recorded under two conditions: speedometer hidden and speedometer revealed. In the second part, the external validity was assessed based on the comparison of actual speed observations from field and simulator. The ecological validity of the simulator setting was assessed through a questionnaire.

Results: Results from both experiments showed correspondence of the driving behavior between the simulator and real-world settings. In general, the profiles for estimated speed and actual speed followed a significantly similar tendency and indicated relative validity in both experiments. Moreover, external absolute validity for speed perception was established on all the requested speeds with speedometer hidden while only for the requested speed of $80 \mathrm{kph}$ with speedometer revealed. Participants' evaluation of the quality and performance of the driving simulator supported the ecological validity of the simulator setting.

Conclusion: The fixed-base driving simulator used in this study can be considered as a useful tool for research on actual speed and speed perception.
\end{abstract}

KEY WORDS: driving simulator; validation; speed perception; speedometer, ecological validity; external validity 


\section{INTRODUCTION}

Injuries and fatalities from road traffic crashes are a major public health problem. They account for the majority of deaths and disabilities due to all forms of injury worldwide (World Health Organization, 2015). These crashes are traditionally explained in function of three causative factors i.e. human operators, infrastructure and vehicle properties. However, it is estimated that in more than $90 \%$ of all road crashes, a human error is involved. Therefore, it is essential to consider human factors in the process of roadway design.

Driving simulators offer a safe and effective environment to incorporate human factors in road safety research (Llopis-Castelló et al., 2016). Simulators can be used for studies which could not be safely done in the real-world situations such as driving under the influence of alcohol and drugs, fatigue, mobile phone use, etc. (Ariën et al., 2013; Daniels et al., 2010; Nilsson, 1993). Driving simulation indeed eliminates all real-life implications one would be exposed to on-road, in case a collision would occur. In addition, a simulator allows control over extraneous variables that affect drivers' behavior, making it a flexible research tool. Moreover, the real-world environment can be replicated in detail in the simulation and compared with alternatively treated scenarios to investigate the impact on drivers' behavior.

The validity of driving simulators has been a discussion point for quite some time already with different results reported in the literature. In simple terms, the issue of simulator validity relates to the extent to which driving behavior observed in a simulated environment corresponds with (or deviates from) real-world driving behavior (Fisher et al., 2011).

Validity testing usually comprises verification of external and ecological validity. External validity relates to whether observed causal relationships can be generalized to different measures, persons, setting, etc. (Calder, Phillips, \& Tybout, 1983). Ecological validity refers to the extent that the research setting and operations resemble the real-world that is being examined (Reis \& Judd, 2000). External (behavioral) validity can be further split into two distinct types, i.e. absolute validity and relative validity (Blaauw, 1982). Absolute validity applies to the case where the difference between the numerical values obtained for behavior observed in the simulator is not statistically significant from those obtained for behavior observed in the real world. Different from that, relative validity is when the difference between behavioral measures from simulated and realworld environments follow the same tendency (without having to be statistically identical). Relative validity is often considered a minimal data quality-related requirement as a substantial proportion of simulator studies focus on the effect of a specific measure or treatment on driving behavior (Godley et al., 2002; Klüver et al., 2016; Törnros, 1998).

The rest of the paper is organized as follows: first, we present a literature review on the topic, which is followed by the study objectives. Next, we outline the methodological details of the study and present the results. After discussion of the findings and identification of the main limitations, we come to a summarizing conclusion.

\section{LITERATURE REVIEW}

Llopis-Castelló et al. (2016) validated a low-cost driving simulator based on continuous speed profiles obtained in a field study and in the simulator, with data collected from 28 participants. Driving speed was significantly higher in the simulated scenario than in the real-world scenario. Relative validity was achieved in their study due to the high correlation between driver behavior in the simulator and the real-world road. Ecological validity was assessed via questionnaires where drivers rated the quality of the virtual environment compared to the real-world as a medium to high (on average). 
Godley et al. (2002) performed a study to validate a driving simulator for research on speeding countermeasures. Participants drove at significantly higher speed in the instrumented car than the simulator (no absolute validity). However, the speed changes in the driving simulator and realworld followed the same tendency which confirmed relative validity. They concluded their driving simulator was a valid research tool to study the impact of speeding countermeasures.

Törnros (1998) conducted a driving simulator validation study for actual speed and lateral position in a road tunnel. Actual speed and lateral position observations were compared for 20 participants in a real tunnel and a replicated tunnel in a driving simulator. The actual speed data was collected without having access to the speedometer. Participants drove faster in the simulated tunnel than in the real tunnel. Based on the results from analysis of variance, the author concluded that absolute validity was not quite satisfactory as the differences were statistically significant. However, the magnitude of speed and lateral position along the roadway segment in simulated and real tunnels was changing following a similar tendency, which according to the author, supported relative validity.

Another study investigated the validity of a motion-based driving simulator for research on driving behavior at the entrance of urban underground roads (Cao et al., 2015). Fifteen subjects participated in the study and mean speed driven in the simulator was significantly higher than that in the real-world. Nevertheless, relative behavioral validity was supported as the observations from simulator and real-world followed a similar tendency. The study confirmed the simulator as a valid tool for the analysis of driver behavior.

Li et al. (2013) conducted a validation study of a driving simulator for physiological signal measures. Fifteen male participants participated in the study having at least two years of driving experience while no experience with a driving simulator. To evaluate the performance of the driving simulator subjectively, a 0-10 (Likert) scale questionnaire was used and resulted in a score of about 8 points. Relative validity for physiological signal measures was achieved based on the comparison between field and driving simulator observations. In addition, absolute validity was obtained in some of the measurement sites by means of paired t-test analyses.

Cornu et al. (2016) performed a validation study of a medium-fidelity fixed-base driving simulator for speed research on a horizontal curve. Data were collected at seven points starting at $495 \mathrm{~m}$ before the curve while ending at $48 \mathrm{~m}$ after the end of the curve. They verified absolute validity by means of bilateral z-tests. Absolute validity could only be supported at one out of seven observation points. However, relative validity was achieved as mean speed from field and simulator observations was in line. Moreover, like in other studies, participants drove faster in the simulator than in the real-world.

Bella (2005) conducted a validation study for work zone design. Observations from field and simulator experiments were compared to determine whether the speed adopted by drivers in the simulator was different from those observed in the field. In their study, the differences between both settings (simulator and real-world) using bilateral z-tests were not statistically significant at each point, which confirmed a high level of absolute validity. Thereafter Bella (2008) performed another validation study for speed research on two-lane rural roads. Relative validity was confirmed, as the speed profiles from the simulator and field observations were following a similar tendency. Meanwhile, absolute validity was achieved on 9 out of the 11 measurement points.

\section{STUDY OBJECTIVES}

In general, most existing driving simulation validation studies addressed external validity through comparison of actual speed between simulators and real world, while ecological validity was often assessed by surveys (Llopis-Castelló et al., 2016; Reimer et al., 2006). Maybe somewhat 


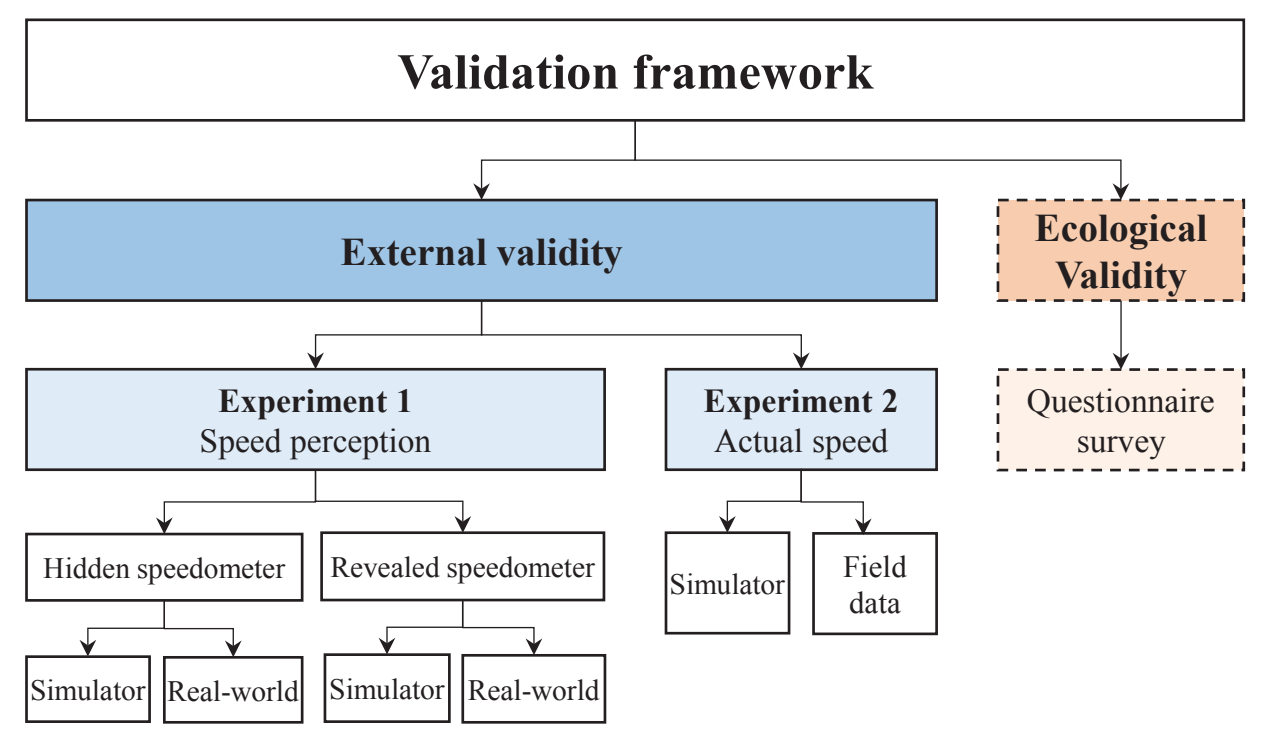

Figure 1. Overview of the validation framework

surprisingly, speed perception has rarely been addressed in the literature even though it is an essential part of how people experience the driving task in a simulated environment. This study aims to test the external and ecological validity of driving simulator setting. External validity testing will not only focus on actual speed but on speed perception as well. Ecological validity will be assessed by means of a questionnaire. The more precise validation framework is further explained in the next section.

\section{METHODS}

Figure 1 shows the overview of the validation framework. External validity was examined by means of two experiments. In the experiment on speed perception, 41 subjects participated to estimate their speed under two different conditions (hidden speedometer and revealed speedometer) in both a real-world setting and a simulator setting. On the other hand, in the experiment on actual speed, field loop data was compared with data collected from 65 subjects in the simulator. Meanwhile the ecological validity was evaluated via questionnaire surveys collected from the same sample participated in the experiment for speed perception.

\subsection{Samples}

\subsubsection{Participants involved in testing external validity of speed perception and ecological validity of simulator setting}

Forty-one subjects (Sample 1) with a valid Qatari driving license participated in the experiment to test the external (i.e. speed perception) and ecological validity of the driving simulator. Participants were informed not to eat or drink (except water) two hours prior to the test. This was to respect the minimum requirements as proposed in a standard simulation sickness questionnaire (Kennedy et al., 1993). Six participants were excluded: for three of them data was missing, one was affected by simulation sickness, and the other two were identified as outliers. Both outliers exceeded the speed limits and were warned to reduce their speed. Thus, 35 participants ( 29 male vs. 6 female) from 16 different nationalities (24 Arabs vs. 11 Non-Arabs) were included in the sample (mean age: 30.59 


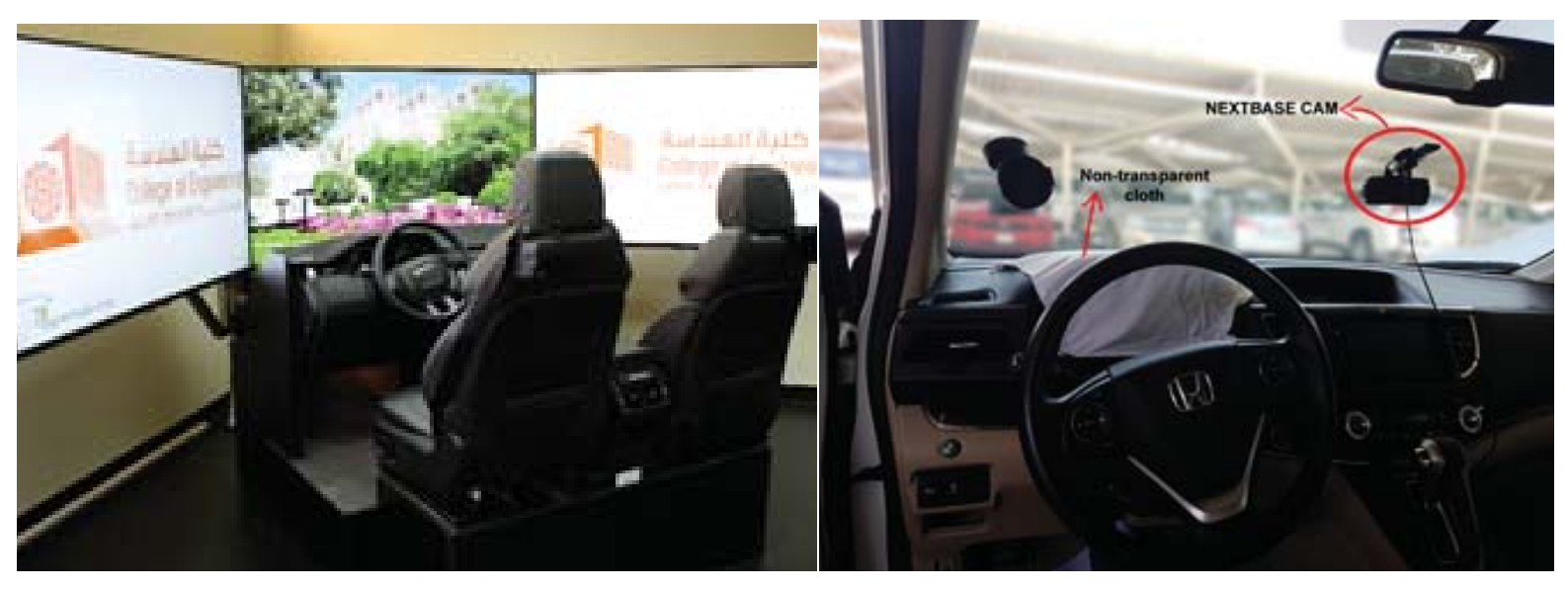

(a) The driving simulator at QTTSC

(b) The test car (Honda CR-V 2016 Model)

Figure 2. The test car and driving simulator used in subjective validation part

years, SD age: 8.7 years, mean driving experience: 8.71 years, and SD driving experience: 6.5 years).

\subsubsection{Participants involved in testing external validity of actual speed'}

Sixty-five subjects (Sample 2) with a valid Qatari driving license participated in the simulation part of the experiment to test the external validity in terms of actual speed. Six participants were excluded: three of them could not complete driving scenarios due to simulation sickness, and the other three participants were filtered out (i.e. drove faster than $140 \mathrm{kph}$ or slower than $50 \mathrm{kph}$ in analysis points). The filtration criteria were set identical to what was done for the field data (Sample 3). Thus, 59 participants ( 45 male vs. 14 female) from 20 different nationalities (30 Arabs vs. 29 Non-Arabs) were included in the sample (mean age: 28.91 years, SD age: 7.4 years, mean driving experience: 8.61 years, and SD driving experience: 6.4 years).

Sample 3 was a group of 147,931 actual speed observations of unknown drivers collected during a three year period (2014-2016) using pneumatic tubes.

\subsection{Materials}

\subsubsection{Driving simulator}

The in-lab part of the experiment to test external validity of speed perception (Experiment 1) and actual speed (Experiment 2) was conducted using the driving simulator at Qatar Transportation and Traffic Safety Center QTTSC, Qatar University (see Figure 2a). The simulator consists of two main components: a) the driving unit - a fixed-base cockpit of a car (Range Rover Evoque) equipped with speedometer, force-feedback steering wheel, pedals, gearbox (automatic transmission), indicators, and b) three large screens covering a 135 degrees of horizontal field of view with a resolution of $5760 \times 1080$ pixels and a $60 \mathrm{HZ}$ refresh rate. The components are interfaced with STISIM Drive ${ }^{\circledR} 3$ along with the CalPot32 program that offers high-speed graphics and sound processing. This simulator setting was also tested for ecological validity.

\subsubsection{Test car}

For the external validation of speed perception, the in-field part of the experiment was conducted using a Honda CR-V 2016-Model car equipped with a NEXTBASE Cam with built-in high-fidelity GPS (see Figure 2b). Speed data for all participants were collected with equipped GPS during the 


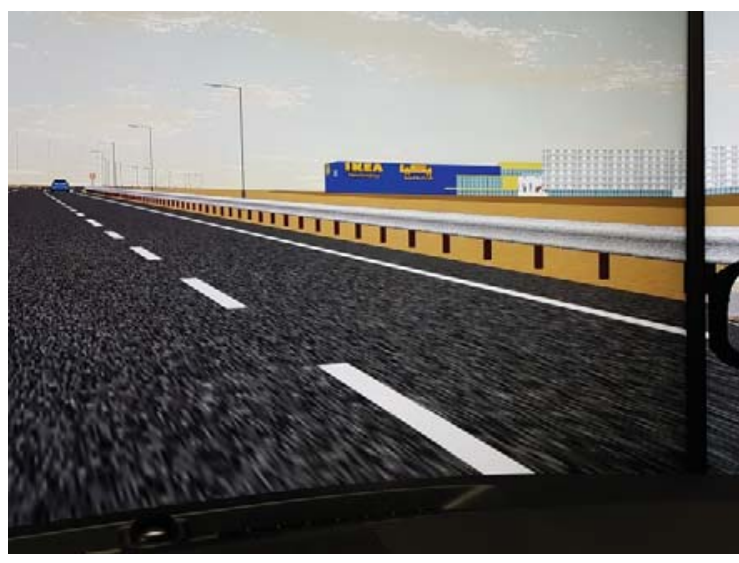

(a) Replicated scenario in the driving simulator

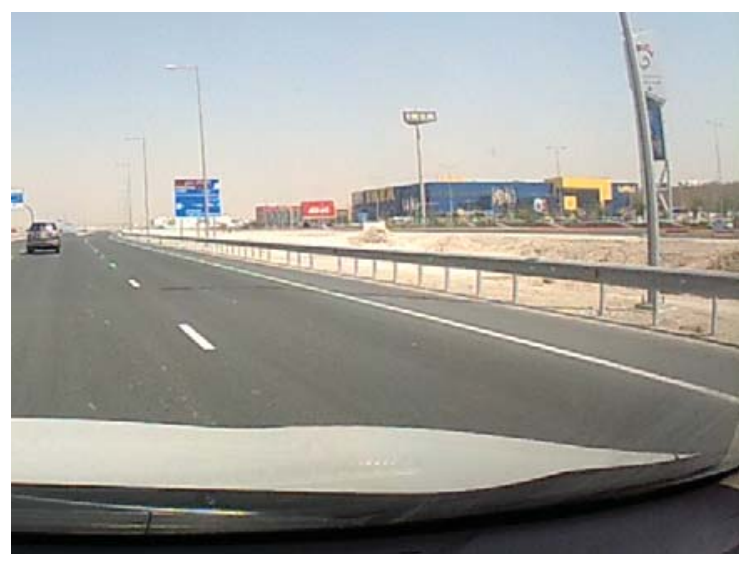

(b) Video footage - Doha Expressway

Figure 3. Doha Expressway - simulator vs real-world images

test period. Furthermore, the cam video recorded the entire test period for each participant. The experimenter used an external GPS to warn drivers if they were violating any speed limit during the test with the hidden speedometer (covered with a non-transparent soft white cloth). Data collection forms were used to record the exact time values. The collected time values were later used to extract travel speed data stored by the GPS.

\subsection{Data collection and procedure}

\subsubsection{External validity test for speed perception}

The overall procedure of Experiment 1 was organized as follows:

1) It is important to mention that before starting the experiments Qatar University's Institutional Review Board (QU-IRB) approval was obtained. Each participant first gave informed consent, and filled in a pre-test questionnaire focusing on sociodemographic variables and driving experience.

2) At the start of the experiment, each participant received the following instructions: "This experiment consists of driving in two environments; real-world and driving simulator, and in two conditions, i.e. hidden and revealed speedometers. Your speed estimation will be collected and evaluated. The real-world observations will take place on Doha expressway in Doha City and the parallel local road. The real-world road segments will be replicated in a driving simulator (see Figure 3 for screenshots). In both environments (real-world and simulator), you will be instructed several times, at what speed to drive where in the first condition the speedometer will be covered and in the second condition, you will be able to see the speedometer. The speed limit on Doha expressway is $120 \mathrm{kph}$ while on the local road it is 80 $\mathrm{kph}$. As soon as you feel that you have reached the requested speed, say "Now" or "Yes" for confirmation".

3) During the real-world observations, each participant was taken to the main test area along with two experimenters in the test car. The speedometer was covered with a non-transparent cloth in the first condition, which was removed in the second condition. The first experimenter (E1) was noting the exact time values from the NEXTBASE Cam screen when subjects confirmed reaching the requested speed "R-speed". The second experimenter (E2) was guiding the participants by telling them at what speed to drive. E2 was also responsible for checking the speed on the external GPS to warn the participants if they were exceeding the speed limit. 
Participants were requested to drive at speeds of 80 and $100 \mathrm{kph}$ on the expressway and at speeds of 50 and $70 \mathrm{kph}$ on the local road. All participants had two trials for each R-speed.

4) In the second part of the experiment, participants were introduced to the driving simulator and were given a practice trial to get familiar with it. Afterwards, each participant received two test conditions, where in the first condition the speedometer was disabled while in the second one it was enabled. Two experimenters supervised the driving trials in the simulator. E1 was sitting beside participants in the driving simulator cockpit informing them the R-speeds. E2 was managing the control station of the driving simulator and was recording the driving speed when participants confirmed reaching the R-speed by E1. Order of the settings (real-world vs simulator) were revised for some of the participants for randomization purposes, implying that some participants drove in the simulator first while others first drove in real-life conditions.

The objective of Experiment 1 was to collect data at four different speed regimes, i.e. $50 \mathrm{kph}$, $70 \mathrm{kph}, 80 \mathrm{kph}$, and $100 \mathrm{kph}$. It was not appropriate for drivers to drive at all of these different speed regimes on a single road stretch. For instance, driving $50 \mathrm{kph}$ on expressways (with speed limit of $100 \mathrm{kph}$ or $120 \mathrm{kph}$ ) would be difficult due to potential conflicts with following vehicles. Furthermore, requesting to drive at a high speed like $100 \mathrm{kph}$ is not acceptable on a road stretch with a speed limit of $80 \mathrm{kph}$. Therefore, two road segments were chosen for the data collection: a segment on the Doha Expressway (speed limit $120 \mathrm{kph}$ ) on which participants were asked to drive at 80 and $100 \mathrm{kph}$; and a segment on the local road running parallel to the Doha expressway (speed limit $80 \mathrm{kph}$ ) where participants were asked to drive at 50 and $70 \mathrm{kph}$.

Since recreation of the exact alignments, cross-section furniture, and the roadside elements in virtual reality can improve realism of a driving experience in the simulator (Bella, 2005, 2008), the two real world road segments were replicated as realistically as possible. To that end, we used STISIM interface (see Figure 3a) based on video footages from the real road environment (see Figure $3 b$ ). Roadside objects such as buildings and streetlights were designed using SketchUp, which is a 3D software (Chen et al., 2015; Levulis et al., 2015; Yang et al., 2013; Zekar \& Khatib, 2018).

\subsubsection{Ecological validity test of the simulator setting}

After the experimental session (Experiment 1) was completed, each participant was asked to complete a paper-based questionnaire, used to verify ecological validity of the simulator setting. This questionnaire probed for feedback/thoughts about the driving experience, and for comparison of the driving simulator with real-world conditions.

\subsubsection{External validity test for actual speed}

To test external validity for actual speed, speed data collected from the field (Sample 3) was compared with speed data obtained from replicated driving scenarios in the simulator (Sample 2). In the simulator, participants drove without instructions to drive at particular speeds.

Actual speed data from the field was collected at midblock points along the Corniche road in Doha City, State of Qatar, during 2014-2016 using pneumatic tubes. The selected points were located at least $300 \mathrm{~m}$ away from the nearest intersection to minimize the impact on speed. The collected speed data was obtained from Muhel Consulting LTD. MetroCount software was used to filter the actual speed data in free-flow conditions for Sedan vehicle class only using a headway of equal or more than 5 seconds (Bella, 2005, 2008).

The simulated environment was designed as consistent as possible with the north bound of the Corniche road in the City of Doha, since required field data were available for north direction only. The scenario was designed in a way to replicate roadway alignments, roadway widths, markings 
Table 1. The characteristics of the analysis points along Corniche Road

\begin{tabular}{c|c|c|c|c}
\hline $\begin{array}{c}\text { Analysis } \\
\text { points * }\end{array}$ & $\begin{array}{c}\text { Year of data } \\
\text { collection } \\
\text { (field observations) }\end{array}$ & $\begin{array}{c}\text { Distance to the } \\
\text { nearest intersection }\end{array}$ & $\begin{array}{c}\text { No of field } \\
\text { observations }\end{array}$ & $\begin{array}{c}\text { No of simulator } \\
\text { observations }\end{array}$ \\
\hline P1 & February, 2016 & $625 \mathrm{~m}$ & 29124 & $59 \times 2$ \\
P2 & June, 2014 & $300 \mathrm{~m}$ & 34088 & $59 \times 2$ \\
P3 & May, 2014 & $500 \mathrm{~m}$ & 32448 & $59 \times 2$ \\
P4 & May, 2014 & $580 \mathrm{~m}$ & 52271 & $59 \times 2$ \\
\hline
\end{tabular}

Note: * The location of the points along the Corniche Road is shown in the figure below.

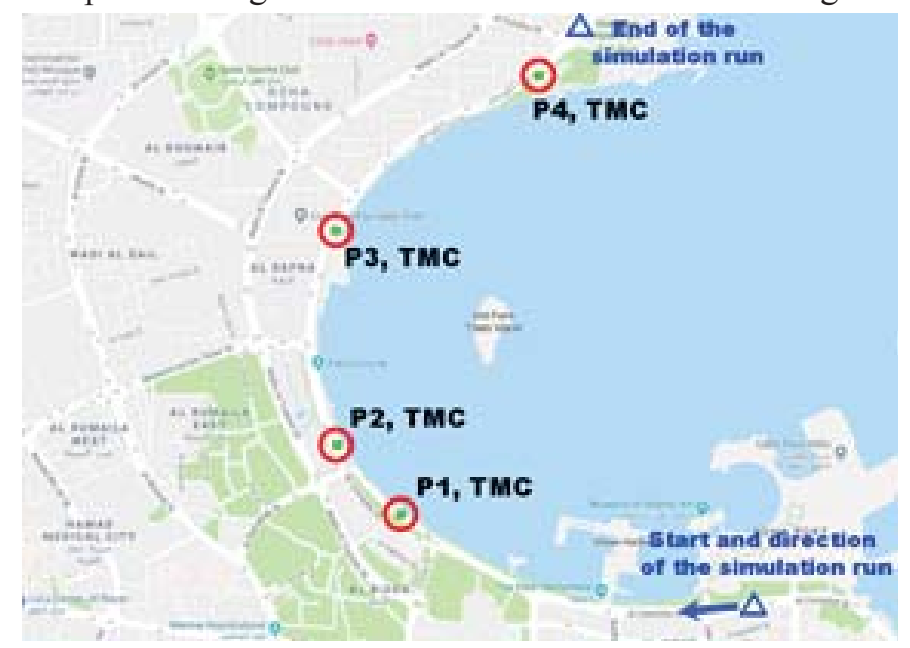

and roadside objects (buildings and vegetation) accurately. Participants were instructed to drive the complete scenario twice. The same four points were located with the help of Google Earth and speed data was extracted on each point twice for each participant. More detailed characteristics of the four analysis points and number of observations on each point are presented in Table 1.

\subsection{Analysis procedure}

\subsubsection{External validity test for speed perception}

Speed data were collected for each R-speed for two settings (simulator and real-world driving) and two conditions (hidden and revealed speedometer). In each setting and condition, for all R-speeds, participants drove twice. Speed data was extracted into spreadsheets as repeated measures for four factors, i.e. requested speed "R-speed" (50, 70, 80 and $100 \mathrm{kph})$, setting (simulator vs reality), condition (hidden vs revealed), and order (first drive vs second drive). A within-subject design was chosen, as each participant drove at each R-speed twice. An ANOVA test was conducted on the variable of interest (i.e. Speed) for the four factors. If the interaction effect was significant, scatter and distribution charts were plotted for further analysis. For all the analyses, the p-value was set at 0.05 to determine statistical significance.

\subsubsection{External validity test for actual speed}

The numbers of field observations on four points are clearly higher than the speed observations from the simulator where data for 59 participants were extracted for the two driving runs. A bilateral Z-test is commonly used for this kind of non-matching test samples in the context of testing absolute external validity of driving simulator data (Bella, 2005; Cornu et al., 2016; Klee et al., 1999; Losa et al., 2013). We formulated the null hypothesis $\mathrm{H}_{0}$ that the field observations and 
Table 2. ANOVA test: within-subjects main and interaction effects (Greenhouse-Geisser)

\begin{tabular}{cccc}
\hline Effect & $\boldsymbol{F}$ & $\boldsymbol{d f s}$ & $\boldsymbol{p}$ \\
\hline Setting & 4.5 & 1,34 & $\mathbf{. 0 4 1}$ \\
Condition & 7.5 & 1,34 & $<.001$ \\
Order & 3.0 & 1,34 & .09 \\
R-speed & 1646.9 & 3,102 & $<.001$ \\
Condition x Setting & $<1$ & 1,34 & .880 \\
Condition x R-speed & 11.8 & 3,102 & $<.001$ \\
Setting x R-speed & 2.6 & 3,102 & 0.074 \\
Condition x Setting x R-speed & 1.1 & 3,102 & .314 \\
\hline
\end{tabular}

simulator observations would not be significantly different (i.e. belong to the same population). Ztests were performed for each point separately to verify absolute external validity for actual speed. For the assessment of relative external validity of actual speed, mean speed values at the four analysis points from both settings (i.e., simulator vs real world) were compared.

\section{RESULTS}

\subsection{External validity - speed perception}

A univariate analysis was performed for the variable of interest i.e. perceived speed (see Table 2). The analysis of variance (ANOVA) shows significant main effects for the factors 'Setting', 'Condition' and 'R-speed', independently. This shows that drivers' traveling speed was significantly different between the simulator drive and real-world drive (i.e. Setting), between the hidden and revealed speedometer (i.e. Condition) and among requested speeds of 50, 70, 80 and $100 \mathrm{kph}$ (i.e. R-speed). Furthermore, the analysis shows the effect of the factor 'Order' was insignificant, which indicates speed was consistent across the first and second driving runs. Although the effects of the factors 'Setting', 'Condition' and 'R-speed' were significantly different, the interaction effects were statistically insignificant and can be described as follows:

- Setting x Condition: Independent of the R-speed, drivers estimated their speed similarly (between the simulator and real-world) under hidden and revealed speedometer conditions, respectively.

- Setting x R-speed: Independent of the factor 'Condition', the estimated speed between the simulator and real-world were not significantly different across the R-speeds. In simpler terms, if we eliminate the factor 'Condition' by averaging the estimated speeds of both conditions, the ANOVA (factors: Setting, R-speed) will provide insignificant results for the interaction effect Setting x R-speed.

- Setting x Condition $\mathrm{x}$ R-speed: The results for this interaction effect are presented in Figures $4 \mathrm{a} \& 4 \mathrm{~b}$ for hidden and revealed speedometer conditions respectively. The figures illustrate the differences between both settings (separate lines) at different R-speeds (four levels) in both conditions (separate graphs). The mean estimated speed profiles show a good correspondence between the speed estimation of drivers in the simulator and in the real-world in two different manners. Firstly, the mean estimated speed is underestimated in the simulator comparing to the real-world in almost all the cases in both conditions. Secondly, the respective mean difference in speed $(\mathrm{d} \mu=\mathrm{Vs}-\mathrm{Vr})$ is not significantly different (t-test: two-tail/paired; $\mathrm{p}$ value $=0.50 ; \mathrm{df}=$ 3 ) between both conditions (separate graphs); hence, following significantly similar tendency. This supports the relative validity of the simulator. 


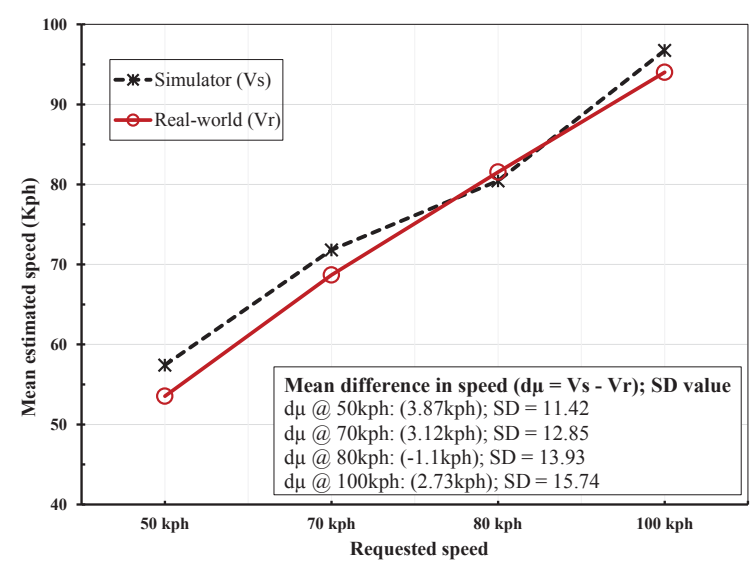

(a) Hidden speedometer

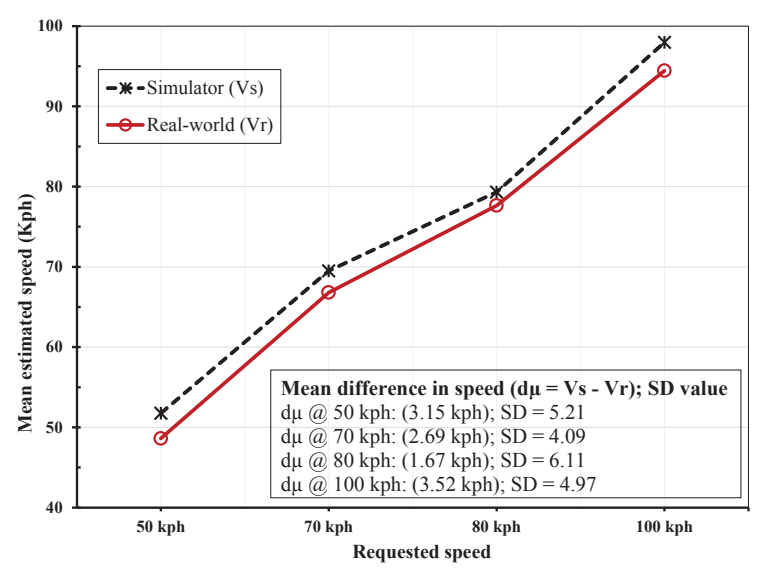

(b) Revealed speedometer

Figure 4. Simulator vs real-world (mean driven speed in $\mathrm{kph}$ ) for hidden and revealed speedometer conditions

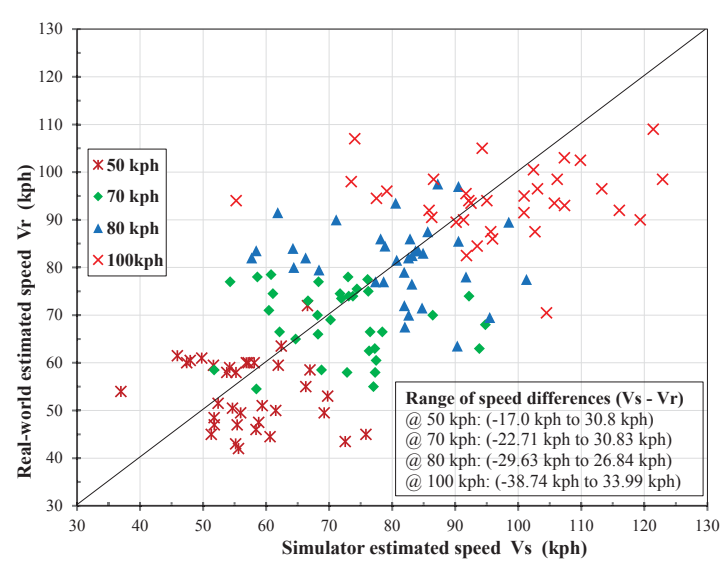

(a) Hidden speedometer

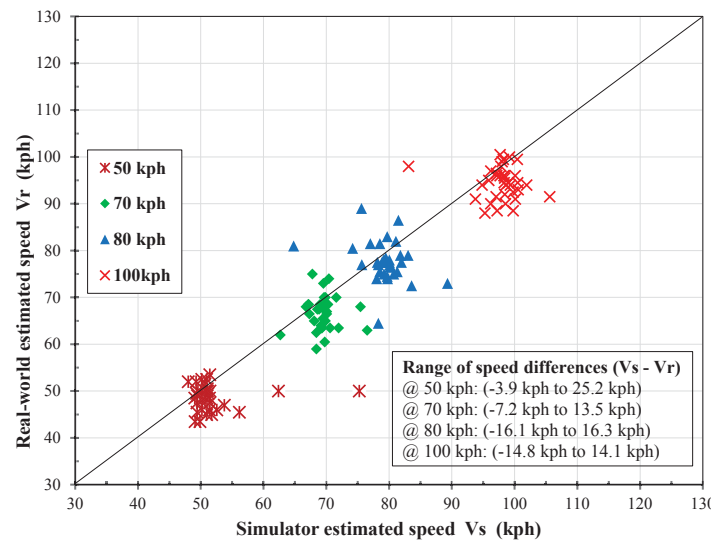

(b) Revealed speedometer

Figure 5. Comparision between measaured speeds in real-world and in driving simulator for hidden and revealed speedometers conditions

To have closer look on the individual speeds of participants in the real-world and the simulator, Figure 5 is presented. It shows a scattered plot of estimated speeds in the simulator and the realworld ( $\mathrm{x}$-axis and $\mathrm{y}$-axis respectively), under hidden and revealed conditions (Figures $5 \mathrm{a} \& 5 \mathrm{~b}$, respectively). Points that are located near to the diagonal line reflect the similarity in speed estimation between simulator and real-world. Points above the diagonal line show drivers who have driven with higher speeds in the real-world compared to the simulator while points below the line show the opposite. It can be seen from Figure 5 that most of the drivers in the real-world and the simulator drove closer to the R-speed when the speedometer was revealed (Figure 5b). In general, this shows the importance of the speedometer allowing drivers to verify their actual speed. As expected, the range for speed differences were larger in hidden speedometer condition compared to the revealed speedometer condition.

To verify absolute external validity for speed perception, we examined the numerical correspondence between the speed observations from the driving simulator and the real-world. Separate t-test analyses (two-tailed; paired) were conducted for each R-speed, and distribution 


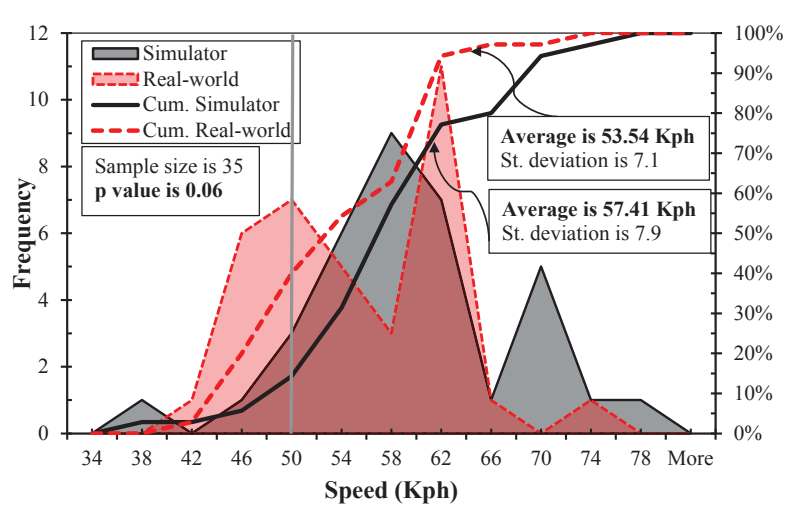

(a) Requested speed of $50 \mathrm{kph}$

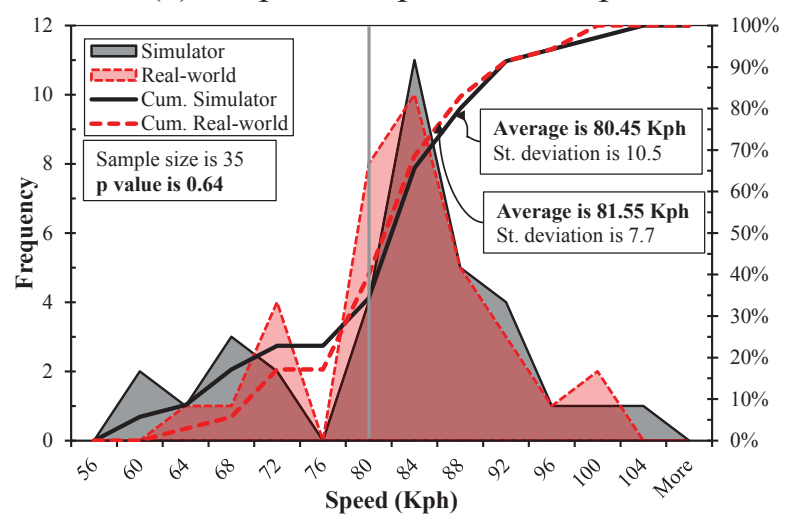

(c) Requested speed of $80 \mathrm{kph}$

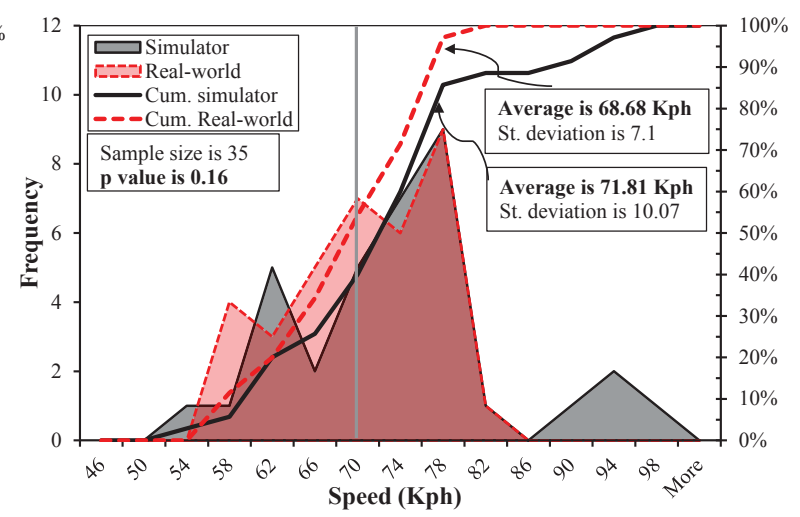

(b) Requested speed of $70 \mathrm{kph}$

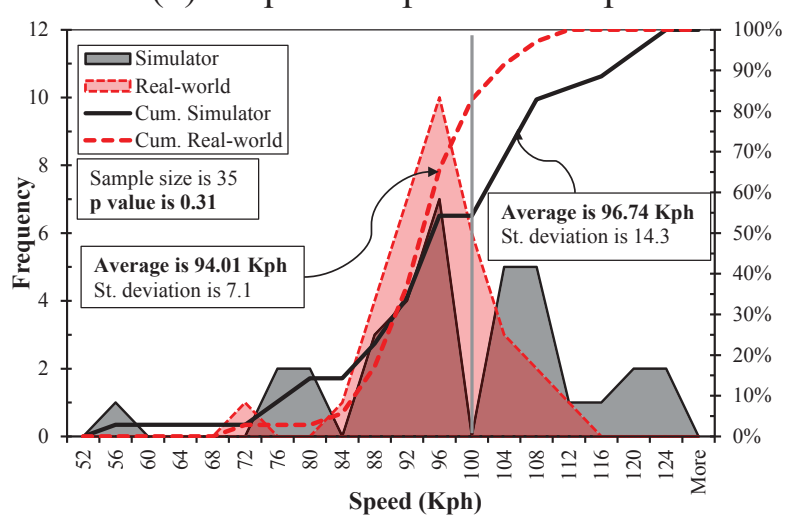

(d) Requested speed of $100 \mathrm{kph}$

Figure 6. Surface area and cumulative distribution diagrams of speeds in hidden speedometer condition

diagrams of estimated speeds were plotted with both settings for all R-speeds separately (Sections $5.1 .1 \& 5.1 .2)$.

\subsubsection{Distribution diagrams - hidden speedometer condition}

In the hidden speedometer condition, participants estimated their perceived speed for 50 and 70 $\mathrm{kph}$ on a local road followed by 80 and $100 \mathrm{kph}$ on Doha expressway, twice in both settings (simulator vs real-world). Figure 6 shows the perceived speed area and cumulative distributions for the real-world and the simulator for the R-speeds of 50, 70, 80 and $100 \mathrm{kph}$ respectively. Interestingly, we found that the speed distributions of real-world and simulator settings at all Rspeeds were not statistically different (at 95\% confidence level). These results, therefore, confirm the external validity of the simulator in absolute terms in condition with the hidden speedometer.

Furthermore, we note that the standard deviations of estimated speeds in the driving simulator are higher compared to those from the real-world observations, which indicates wider range of perceived speeds by participants in the driving simulator than in real-world. We also note in Figure 6(a-d) that the speed distributions are moving to the left as the R-speed increases. This indicates that with the increase of R-speed, most of the drivers tend to overestimate their perceived speed and drive slower than the R-speed. 


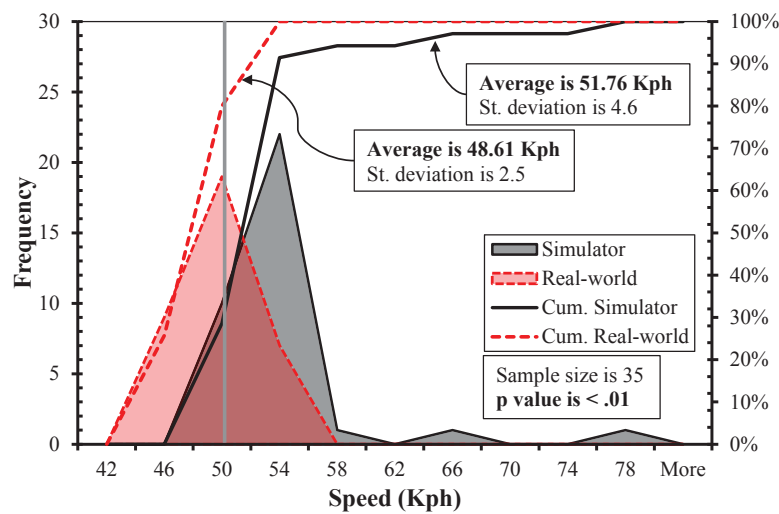

(a) Requested speed of $50 \mathrm{kph}$

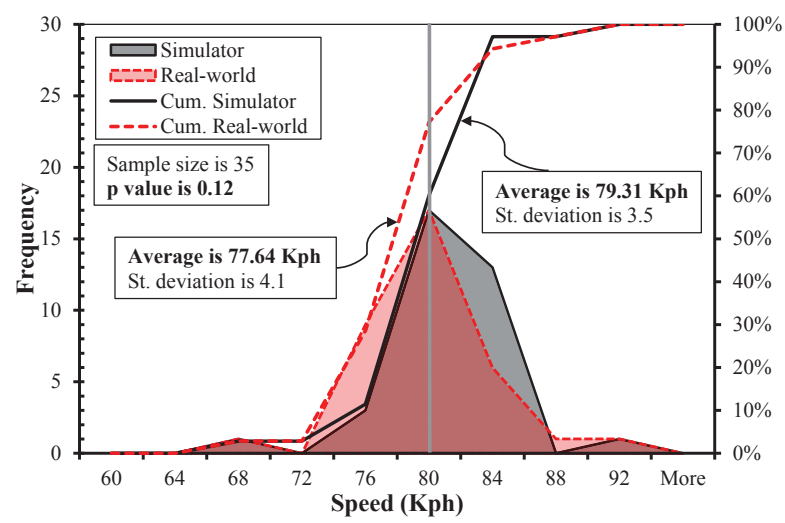

(c) Requested speed of $80 \mathrm{kph}$

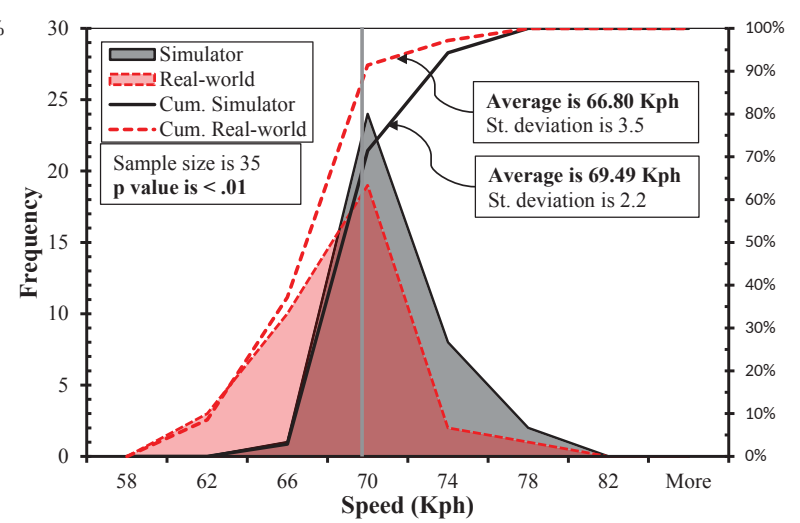

(b) Requested speed of $70 \mathrm{kph}$

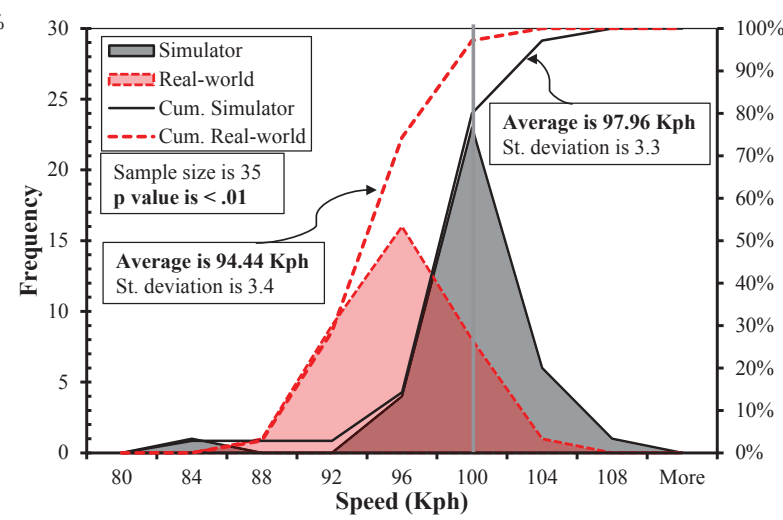

(d) Requested speed of $100 \mathrm{kph}$

Figure 7. Surface area and cumulative distribution diagrams of speeds in revealed speedometer condition

\subsubsection{Distribution diagrams - speedometer revealed condition}

Figure 7 presents the estimated speed area and cumulative distributions in revealed condition for the R-speeds. Unexpectedly, results observed from the separate t-tests analyses between both settings were significantly different for all the R-speeds, except for $80 \mathrm{kph}(\mathrm{p}$-value $=0.12$ ). Participants drove significantly slower in the real-world compared to the simulator. Additionally, the average estimated speeds in the simulator were closer to the R-speeds compared to those in the real-world. On the other hand, the standard deviations for the estimated speeds in the revealed condition were significantly smaller than in the hidden condition. Consistent with results for the hidden speedometer condition, areas moved little to the left when R-speed increased (See Figure $7(\mathrm{a}-\mathrm{d})$ ). This indicates an inverse relationship between the requested and perceived speeds in both settings (simulator and real-world).

\subsection{External validity - actual speed}

Table 3 presents a summary of the observed results obtained for the bilateral Z-tests for the four analysis points along the Corniche Road. Results show that none of the $|Z|$ values is smaller than the critical $\mathrm{Zc}$ value. Therefore, we can reject the hypothesis that the field and simulator observations belong to the same population. The differences between field and simulator observations are statistically significant and hence, no absolute validity was obtained for actual speed. Furthermore, mean speed from the simulator (Vs) was significantly higher than the mean 
Table 3. Results of bilateral Z-tests for the actual speeds of the field and the driving simulator

\begin{tabular}{c|ccc|ccccc}
\hline \multirow{2}{*}{$\begin{array}{c}\text { Analysis } \\
\text { point }\end{array}$} & \multicolumn{2}{|c|}{ Simulator (Vs) } & \multicolumn{2}{|c|}{ Field (Vf) } & \multicolumn{4}{c}{ Z-tests results } \\
\cline { 2 - 7 } & Mean & SD & Mean & SD & $|\mathrm{Z}|$ & $\mathrm{Zc}$ & p value & Comment \\
\hline P1 & 81.16 & 8.41 & 70.44 & 13.12 & 9.69 & 1.96 & $<.01$ & $\mathrm{H}_{0}$ rejected \\
P2 & 78.24 & 7.03 & 65.79 & 9.62 & 13.46 & 1.96 & $<.01$ & $\mathrm{H}_{0}$ rejected \\
P3 & 81.60 & 8.73 & 70.68 & 12.79 & 9.51 & 1.96 & $<.01$ & $\mathrm{H}_{0}$ rejected \\
P4 & 82.99 & 10.05 & 71.46 & 10.44 & 8.73 & 1.96 & $<.01$ & $\mathrm{H}_{0}$ rejected \\
\hline
\end{tabular}

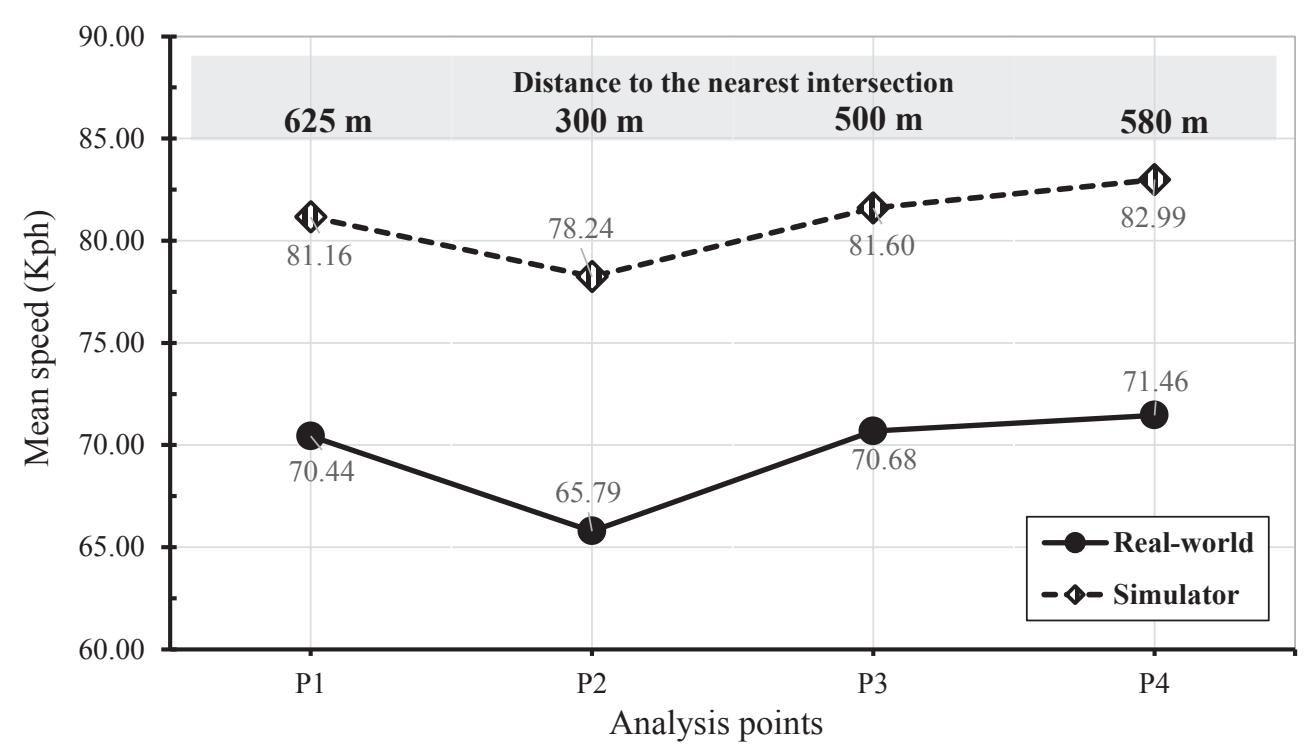

Figure 8. Mean speed values on four analysis points

speed values from field observations at all the points. The standard deviations for speed observations were higher for field observations than for simulator.

However, to evaluate the relative validity, mean speed values from both observations were plotted together as shown in Figure 8. Separate t-test analyses were conducted before comparing the results from both cases. Although there are significant differences between mean values of both cases, the drop in the speed observed between the simulator and field was not significantly different (t-test: two-tail/two-samples with unequal variance; $p$ value $=0.94 ; \mathrm{df}=3$ ). The mean speed drops in both cases at point 2 (Figure 8), where the distance to the nearest intersection was shortest (i.e. $300 \mathrm{~m}$ ) which can be attributed to impact of traffic flow from the intersection.

\subsection{Ecological validity}

After completion of the experimental sessions (Experiment 1), the ecological validity of the driving simulator was evaluated by means of a questionnaire. The questionnaire was divided into two parts. In the first part, subjects compared driving in the simulator with driving in reality, while in the second part they compared the performance between the different components of the driving simulator and a real car. All items were measured on a 7-point Likert scale. As shown in Table 4, the results indicate that subjects were comfortable with the driving simulator (Mean: 4.94) and gave the highest rating for overall general comparison (Mean: 5.41). Speed perception was also rated higher than the middle value (i.e. 4), which compliments the validation results that we obtained from experiment 1 (simulator vs reality). All examined measures for comparison of the performance of the driving simulator with a real car were higher than the middle value (i.e. 4) 
Table 4. Post-test Questionnaire for the evaluation of the driving simulator $(1=$ not effective, 7 $=$ highly effective)

\begin{tabular}{|c|c|c|c|c|c|c|c|c|c|c|c|}
\hline & & \multicolumn{7}{|c|}{$\begin{array}{l}\text { No. of responses for each rating level } \\
\text { of ratings }\end{array}$} & \multirow{2}{*}{$\begin{array}{l}\text { Mean } \\
\text { Ratings }\end{array}$} & \multirow{2}{*}{$\begin{array}{l}\text { SD } \\
\text { Ratings }\end{array}$} & \multirow{2}{*}{$\begin{array}{l}\text { Sample } \\
\text { Size }\end{array}$} \\
\hline & & 1 & 2 & 3 & 4 & 5 & 6 & 7 & & & \\
\hline \multirow{3}{*}{$\begin{array}{l}\text { General } \\
\text { comparison }\end{array}$} & Overall & 1 & 1 & 4 & 2 & 7 & 7 & 12 & 5.14 & 1.6 & 34 \\
\hline & Comfort & 2 & 3 & 5 & 1 & 7 & 8 & 9 & 4.94 & 1.8 & 35 \\
\hline & Speed perception & 3 & 7 & 6 & 3 & 3 & 4 & 8 & 4.17 & 2.1 & 34 \\
\hline \multirow{7}{*}{$\begin{array}{l}\text { Performance } \\
\text { comparison }\end{array}$} & Overall & 0 & 2 & 8 & 7 & 8 & 6 & 3 & 4.49 & 1.4 & 34 \\
\hline & Steering wheel & 2 & 2 & 4 & 7 & 3 & 13 & 4 & 4.77 & 1.7 & 35 \\
\hline & Accelerator & 2 & 8 & 2 & 5 & 9 & 2 & 7 & 4.28 & 1.9 & 35 \\
\hline & Brake & 2 & 4 & 5 & 6 & 9 & 3 & 6 & 4.40 & 1.7 & 35 \\
\hline & Graphics & 1 & 7 & 4 & 2 & 12 & 7 & 2 & 4.31 & 1.6 & 35 \\
\hline & Sound of engine & 2 & 5 & 4 & 8 & 2 & 8 & 5 & 4.38 & 1.8 & 34 \\
\hline & Sound of environment & 3 & 5 & 6 & 7 & 6 & 5 & 2 & 3.91 & 1.6 & 34 \\
\hline
\end{tabular}

except for sound from the environment (Mean: 3.91). The steering wheel was rated highest (Mean: 4.77) among the components of a driving simulator.

\section{DISCUSSION}

Table 5 presents a summary matrix of the validation findings i.e. two types of validation (i.e. external and ecological) in two parts (i.e. absolute and relative). Overall, the results showed a good correspondence of the driving behavior in the simulator compared with the real-world for both, speed perception and actual speed.

\subsection{Relative validation}

Relative validity has been achieved in both parts of the validation i.e. the external and ecological validation (Table 5). The external relative validity for speed perception has been well established on both conditions (i.e. hidden and revealed speedometer). The estimated mean speed profiles and the respective mean difference (between both conditions) revealed comparatively similar tendency across various levels of R-speeds (see Figure. $4 \mathrm{a} \& 4 \mathrm{~b}$ ). The lowest mean of speed differences between requested and driven speeds were observed at the R-speed of $80 \mathrm{kph}$ in both hidden and revealed speedometer conditions, which is rational since most of the urban arterial roads in Doha have speed limit of $80 \mathrm{kph}$. The variations among drivers' speed estimation are lower in revealed speedometer condition compared to the hidden condition, which is reasonable. Interesting is that, on average, many participants drove slower than the R-speeds in the revealed speedometer condition while they drove faster than the R-speeds in the hidden speedometer condition. This is in accordance with previous studies (e.g. Denton, 1966; Recarte \& Nunes, 1996; Triggs \& Berenyi, 1982), reporting that drivers generally underestimate speed and drive faster than the R-speeds if they do not have access to the speedometer.

In addition, the external relative validity has also been established for actual speed. The speed profiles showed a good correspondence between both field and simulator (Figure 8). The magnitude of the differences and drop in the respective speeds remained significantly consistent on all analysis points. However, significant differences between measured speeds values in the field and in the simulator were found. This can be attributed to the fact that there was a small number of observations in simulator data with higher speed values. Participants underestimate their speed in the simulator, which made them drive faster than the real-world (Bella, 2008; Branzi et al., 2017; 
Table 5. Summary of the Absolute and Relative validations for speed perception and actual speed

\begin{tabular}{|c|c|c|c|c|c|c|c|c|c|c|c|c|c|}
\hline \multirow{3}{*}{$\begin{array}{l}\text { Validation } \\
\text { part }\end{array}$} & \multicolumn{8}{|c|}{$\begin{array}{l}\text { External validity } \\
\text { (speed perception) }\end{array}$} & \multicolumn{4}{|c|}{$\begin{array}{l}\text { External validity } \\
\text { (actual speed) }\end{array}$} & \multirow{2}{*}{$\begin{array}{c}\text { Ecological validity } \\
\text { Results from the } \\
\text { post-test } \\
\text { questionnaire } \\
\end{array}$} \\
\hline & \multicolumn{4}{|c|}{$\begin{array}{l}\text { Requested speeds } \\
\text { (Hidden speedometer) }\end{array}$} & \multicolumn{4}{|c|}{$\begin{array}{c}\text { Requested speeds } \\
\text { (Revealed speedometer) }\end{array}$} & \multicolumn{4}{|c|}{$\begin{array}{l}\text { Analysis points w.r.t } \\
\text { distance to the nearest } \\
\text { intersection }\end{array}$} & \\
\hline & 50 & 70 & 80 & 100 & 50 & 70 & 80 & 100 & $\mathrm{P} 1$ & $\mathrm{P} 2$ & P3 & $\mathrm{P} 4$ & 1-7 Likert Scale \\
\hline $\begin{array}{l}\text { Absolute } \\
\text { validity }\end{array}$ & $\begin{array}{c}\text { Ye } \\
\text { s }\end{array}$ & $\begin{array}{c}\mathrm{Ye} \\
\mathrm{s}\end{array}$ & $\begin{array}{c}\text { Ye } \\
\mathrm{s}\end{array}$ & $\begin{array}{c}\mathrm{Ye} \\
\mathrm{S}\end{array}$ & No & No & $\begin{array}{c}\mathrm{Ye} \\
\mathrm{s}\end{array}$ & No & No & No & No & No & Not applicable \\
\hline $\begin{array}{l}\text { Relative } \\
\text { validity }\end{array}$ & \multicolumn{8}{|c|}{$\begin{array}{l}\text { Yes, based on the mean speed profiles of the } \\
\text { requested speeds in both conditions \& based on the } \\
\text { significantly similar respective mean difference } \\
\text { between both conditions }\end{array}$} & \multicolumn{4}{|c|}{$\begin{array}{l}\text { Yes, based on the } \\
\text { significant similar drop } \\
\text { in the mean speed } \\
\text { between simulator and } \\
\text { field w.r.t distance to } \\
\text { the nearest intersection }\end{array}$} & $\begin{array}{l}\text { Yes, based on the } \\
\text { subjective } \\
\text { evaluation of the } \\
\text { quality and } \\
\text { performance of the } \\
\text { driving simulator }\end{array}$ \\
\hline
\end{tabular}

Colombet et al., 2011; Hurwitz et al., 2005; Meuleners \& Fraser, 2015). According to Bella (2008), this underestimation is mainly due to lack of risk and lack of lateral acceleration provided by the simulator.

The drivers' evaluation of the quality and performance of the driving simulator confirms the ecological validity of the simulator settings. The ratings given for all components of the simulator provide enough evidence that the settings of the simulator are comparable with the settings offered by a real car.

\subsection{Absolute validation}

The external validity for speed perception in absolute terms was assessed by t-test analyses. Interestingly, absolute validity was achieved for all the R-speeds in hidden speedometer condition (Table 5), where drivers perceive statistically similar speeds between simulator and real-world. This result indicates that the simulator yields great visual and auditory performances including graphics, visual field angle, engine noise and sound from environment etc. Although the differences in the means of speeds between the simulator and real world in revealed condition at all R-speeds were little (ranges from 1.5 to $3.5 \mathrm{kph}$ as shown in Figure 4), statistical significant differences were found at 50,70, and 100kph (Table 5). A possible explanation could be that the statistical tests gave significant results based on a small difference in mean speeds between simulator and real-world, because the variations among the participants' estimated speeds were too little.

Results from Z-test analyses confirm that no external absolute validity was achieved for actual speed, which was expected due to the dissimilarities of the characteristics between observations from both cases. The field data were collected a few years before at different conditions (i.e. traffic volume, driver population, driving behavior, and road environment etc.). This is in accordance with most of the previous studies on validation of driving simulators, which could not achieve perfect absolute validity.

It is important to note that this study had some limitations. A single test car was used in the experiment for collecting speed perception data for external validity. Furthermore, participants were accompanied by two experimenters, which could probably influence their driving behavior due to the observer effect. Moreover, actual speed data from the simulator, with replicated scenario of the current layout and traffic condition of Corniche Road, was compared with the field 
observations at the same road collected 2 to 4 years earlier with possibly different layout and traffic conditions. This can have significant impact on the results of the actual speed comparisons.

\section{CONCLUSION}

This study was designed to investigate the external and ecological validity of a driving simulator. In general, we conclude that driving simulators can be considered as useful tools for research on driving speed (actual speed and speed perception). Through the analysis presented in this paper, the following more specific conclusions can be drawn:

- The external validation was performed for speed perception and actual speed by comparing the observations from real-world and the driving simulator. The external relative validity was obtained in both parts since the results clearly show that the mean speed profiles were close and following the same tendencies. On the other hand, the external absolute validity for speed perception was also obtained for 5 out of 8 R-speeds (4 R-speed x 2 Condition).

- The ecological validation was assessed through the drivers' subjective evaluation by post-test questionnaire and the results support the ecological validity of the driving simulator.

Overall, based on the above analysis, we conclude that the simulator is a valid tool applicable for research on driving speed.

\section{ACKNOWLEDGEMENTS}

This publication was made possible by the NPRP award [NPRP 9-360-2-150] from the Qatar National Research Fund (a member of Qatar Foundation). The statements made herein are solely the responsibility of the author[s]. Furthermore, authors are deeply thankful to Muhel Consulting Limited for providing part of the data used in this study.

\section{REFERENCES}

Ariën, C., Jongen, E. M. M., Brijs, K., Brijs, T., Daniels, S., \& Wets, G. (2013). A simulator study on the impact of traffic calming measures in urban areas on driving behavior and workload. Accident Analysis \& Prevention, 61, 43-53. doi:https://doi.org/10.1016/j.aap.2012.12.044

Bella, F. (2005). Validation of a Driving Simulator for Work Zone Design. Transportation Research Record: Journal of the Transportation Research Board, 1937, 136-144. doi:10.3141/1937-19

Bella, F. (2008). Driving simulator for speed research on two-lane rural roads. Accident Analysis \& Prevention, 40(3), 1078-1087. doi:https://doi.org/10.1016/j.aap.2007.10.015

Blaauw, G. J. (1982). Driving experience and task demands in simulator and instrumented car - a validation study. HUM FACTORS, V 24(N 4), 473-486.

Branzi, V., Domenichini, L., \& La Torre, F. (2017). Drivers' speed behaviour in real and simulated urban roads - A validation study. Transportation Research Part F: Traffic Psychology and Behaviour, 49, 1-17. doi:https://doi.org/10.1016/j.trf.2017.06.001

Calder, B. J., Phillips, L. W., \& Tybout, A. M. (1983). The concept of external validity. Journal of Consumer Research(10(1)), 112-114.

Cao, C., Wang, J., \& Luo, Y. (2015). Driving simulator validation for research on driving behavior at entrance of urban underground road. Paper presented at the 3rd International Conference on Transportation Information and Safety, ICTIS 2015.

Chen, K. B., Xu, X., Lin, J.-H., \& Radwin, R. G. (2015). Evaluation of older driver head functional range of motion using portable immersive virtual reality. Experimental Gerontology, 70, 
150-156. doi:https://doi.org/10.1016/j.exger.2015.08.010

Colombet, F., Paillot, D., Mérienne, F., \& Kemeny, A. (2011). Visual Scale Factor for Speed Perception. Journal of Computing and Information Science in Engineering, 11(4), 041010041010-041016. doi:10.1115/1.4005449

Cornu, J., Arien, C., Gardeniers, B., Brijs, K., Daniels, S., Brijs, T., \& Wets, G. (2016). Driving simulator validation for speed research on a horizontal curve. Paper presented at the TRB 95th Annual Meeting Compendium of Papers.

Daniels, S., Vanrie, J., Dreesen, A., \& Brijs, T. (2010). Additional road markings as an indication of speed limits: Results of a field experiment and a driving simulator study. Accident Analysis \& Prevention, 42(3), 953-960. doi:https://doi.org/10.1016/j.aap.2009.06.020

Denton, G. G. (1966). A Subjective Scale of Speed when Driving a Motor Vehicle. Ergonomics, 9(3), 203-210. doi:10.1080/00140136608964371

Fisher, D. L., Rizzo, M., Caird, J. K., \& Lee, J. D. (2011). Handbook of Driving Simulation for Engineering, Medicine, and Psychology. CRC Press - Taylor \& Francis Group.

Godley, S. T., Triggs, T. J., \& Fildes, B. N. (2002). Driving simulator validation for speed research. Accident Analysis \& Prevention, 34(5), 589-600. doi:https://doi.org/10.1016/S00014575(01)00056-2

Hurwitz, D. S., Knodler, M. A., \& Dulaski, D. M. (2005). Speed Perception Fidelity in a Driving Simulator Environment. Paper presented at the Driving Simulation Conference, North America.

Kennedy, R. S., Lane, N. E., Berbaum, K. S., \& Lilienthal, M. G. (1993). Simulator Sickness Questionnaire: An Enhanced Method for Quantifying Simulator Sickness. The International Journal of Aviation Psychology, 3(3), 203-220. doi:10.1207/s15327108ijap0303_3

Klee, H., Bauer, C., Radwan, E., \& Al-Deek, H. (1999). Preliminary validation of driving simulator based on forward speed. Transportation Research Record(1689), 33-39.

Klüver, M., Herrigel, C., Heinrich, C., Schöner, H.-P., \& Hecht, H. (2016). The behavioral validity of dual-task driving performance in fixed and moving base driving simulators. Transportation Research Part F: Traffic Psychology and Behaviour, 37, 78-96. doi:https://doi.org/10.1016/j.trf.2015.12.005

Levulis, S. J., DeLucia, P. R., \& Jupe, J. (2015). Effects of oncoming vehicle size on overtaking judgments. Accident Analysis \& Prevention, 82, 163-170. doi:https://doi.org/10.1016/j.aap.2015.05.024

Li, J., Zhao, X., Xu, S., Ma, J., \& Rong, J. (2013). The Study of Driving Simulator Validation for Physiological Signal Measures. Procedia - Social and Behavioral Sciences, 96, 2572-2583. doi:https://doi.org/10.1016/j.sbspro.2013.08.288

Llopis-Castelló, D., Camacho-Torregrosa, F. J., Marín-Morales, J., Pérez-Zuriaga, A. M., García, A., \& Dols, J. F. (2016) Validation of a low-cost driving simulator based on continuous speed profiles. Vol. 2602. Transportation Research Record (pp. 104-114): National Research Council.

Losa, M., Frendo, F., Cofrancesco, A., \& Bartolozzi, R. (2013). A procedure for validating fixedbase driving simulators. Transport, 28(4), 420-430. doi:10.3846/16484142.2013.867281

Meuleners, L., \& Fraser, M. (2015). A validation study of driving errors using a driving simulator. Transportation Research Part F: Traffic Psychology and Behaviour, 29, 14-21. doi:https://doi.org/10.1016/j.trf.2014.11.009

Nilsson, L. (1993). Behavioural Research in an Advanced Driving Simulator - Experiences of the VTI System. Proceedings of the Human Factors and Ergonomics Society Annual Meeting, 37(9), 612-616. doi:10.1177/154193129303700921 
Recarte, M. A., \& Nunes, L. M. (1996). Perception of Speed in an Automobile: Estimation and Production (Vol. 2).

Reimer, B., D’Ambrosio, L. A., Coughlin, J. F., Kafrissen, M. E., \& Biederman, J. (2006). Using self-reported data to assess the validity of driving simulation data. Behavior Research Methods, 38(2), 314-324. doi:10.3758/BF03192783

Reis, H. T., \& Judd, C. M. (2000). Handbook of research methods in social and personality psychology. Cambridge, U.K: Cambridge University Press.

Törnros, J. (1998). Driving behaviour in a real and a simulated road tunnel-a validation study. Accident Analysis \& Prevention, 30(4), 497-503. doi:https://doi.org/10.1016/S00014575(97)00099-7

Triggs, T. J., \& Berenyi, J. S. (1982). Estimation of automobile speed under day and night conditions (Vol. 24).

World Health Organization. (2015). Global status report on road safety 2015. Retrieved from http://www.who.int/violence_injury_prevention/road_safety_status/2015/en/

Yan, X., Abdel-Aty, M., Radwan, E., Wang, X., \& Chilakapati, P. (2008). Validating a driving simulator using surrogate safety measures. Accident Analysis \& Prevention, 40(1), 274-288. doi:https://doi.org/10.1016/j.aap.2007.06.007

Yang, Z., Yan, X., Guo, D., \& Lin, P. (2013). Framework of Automatic Driving Simulation Scene Development Based on Input of Road Design Parameters (Vol. 5).

Zekar, A., \& Khatib, S. E. (2018). Development and assessment of simplified building representations under the context of an urban energy model: Application to arid climate environment. Energy and Buildings, 173, 461-469. doi:https://doi.org/10.1016/j.enbuild.2018.04.030 